\title{
When discourse matches syntax: On meta-informative centering theory and discourse coherence in the recent history of English
}

\author{
ANA ELINA MARTÍNEZ INSUA* \\ Universidade de Vigo
}

Received: 13 April 2011 / Accepted: 27 October 2011

\begin{abstract}
This paper is concerned with how there-constructions may have helped to achieve discourse coherence in the recent history of English. From the theoretical framework of Meta-Informative Centering Theory (MIC) the paper explores the possibility to establish a relation between the syntactic structures under analysis and the distinction between 'smooth-shift' and 'rough-shift' transitions from one centre of attention to another (Brennan, Friedman \& Pollard, 1987). This will help, ultimately, to investigate the interaction between centering and MIC theories, word order and information structure in a 'non-free' word order language such as English. A corpusdriven analysis of the behaviour of spoken and written there-constructions from late Middle English to Present Day English will show their capacity to function either as highly coherent structures that continue with the same local topic as the previous utterance(s), or as means to shift the local focus of attention.
\end{abstract}

\section{KEYWORDS}

Discourse coherence, Meta-Informative Centering Theory, there-construction, (global and local) centre of attention.

\section{RESUMEN}

Este artículo estudia cómo las construcciones con there pueden haber contribuido a la creación de coherencia discursiva a lo largo de la historia del inglés. Desde el marco teórico de la denominada Meta-Informative Centering Theory (MIC), exploraremos la posibilidad de establecer conexiones entre la estructura sintáctica estudiada y diversos tipos de transiciones entre centros de atención (Brennan, Friedman \& Pollard, 1987). En última instancia, esto contribuirá a la mejor caracterización de la interacción entre las teorías MIC y Centering Theory, el orden de palabras y la estructura de la información en una lengua con orden de palabras rígido. El estudio de corpus que aquí se presenta se basa en datos extraídos de muestras de inglés oral y escrito correspondientes al periodo que va del Inglés Medio tardío al Inglés Contemporáneo. Los datos muestran la capacidad de las construcciones con there para funcionar bien como estructuras altamente coherentes que mantienen el tópico local previo, o bien como instrumentos para cambiar el centro de atención local.

PALABRAS CLAVE

Coherencia discursiva, Meta-Informative Centering Theory, construcciones con there, centro de atención (global y local)

\footnotetext{
*Address for correspondence: Ana Elina Martínez Insua. Departamento de Filoloxía Inglesa, Francesa e Alemá, Campus de Lagoas-Marcosende. .36310, Vigo. Spain. E-mail: minsua@uvigo.es
} 


\section{INTRODUCTION}

Speakers have a number of alternatives as far as the organization and the design of the constituents which materialise a proposition in English are concerned. Each unit of semantic content at the informative layer of language may correspond to different forms within the meta-informative layer, understanding the labels 'informative' and 'meta-informative' as they are understood in the theoretical framework of the Meta-Informative Centering Theory ${ }^{1}$. Discourse coherence plays a crucial role in such a decision-making process, the position of the utterances in the surrounding discourse and their propositional relation to the immediately preceding co(n)-text having a marked relevance in the process.

The present paper approaches the so-called there-construction (hereafter, TC) from the perspective of the Meta-Informative Centering Theory (MIC Theory, henceforth). Based on Centering Theory (Joshi \& Kuhn, 1979; Joshi \& Weinstein, 1981; Grosz, 1977; Sidner, 1979; Grosz \& Sidner, 1986; Walker, Joshi \& Prince, 1998, among others), according to which centering is "a model of the complexity of the inferences required to integrate the meaning of an utterance into the meaning of the preceding discourse", "a model of some aspects of local focus" (Walker, Joshi \& Prince, 1998: 2), MIC Theory focuses on the 'meta-information' as "the sequential ordering of information" (Wlodarczyk \& Wlodarczyk, forthcoming: 1). Given that the semantic situation is regarded as naturally non-linear, the MIC Theory regards the meta-informative level as crucial for the achievement of the ordering of non-linear mental representations as texts (Wlodarczyk \& Wlodarczyk, forthcoming: 1).

From such a perspective we will contend that TCs cannot be understood as mere syntactic variants or transformations of basic constructions without there, as was suggested in early generative accounts (see Harris, 1957, among others). On the contrary, in the present paper we will study TCs within the framework of the MIC Theory and its predictions about the distribution of full NPs and pronouns in naturally occurring discourse (see Walker, Joshi \& Prince, 1998). We will analyse TCs and their discourse role(s) in terms of the 'backwardlooking', 'forward-looking' and 'preferred centres' that the MIC Theory proposes. Our ultimate aim is to investigate to what extent connections could be established between TCs and the distinction between 'smooth-shift' and 'rough-shift' transitions from one centre of attention (hereafter, CA) to another (Brennan, Friedman \& Pollard, 1987). This, in turn, may help us to investigate the interaction between Centering Theory, word order and information structure in a 'non-free' word order language such as English.

Throughout the paper we will describe the evolution of the TC from late Middle English (IME) to Present-Day English (PDE), providing details on the data analysed, the findings, plus some tentative conclusions. As pointed out, the analysis of the data will focus on the connections that may be established between Centering, informational structure and discourse coherence as the communicative potential of the utterance at issue. The paper is organised as follows: Section 2 contains some brief notes about the theoretical framework employed (2.1.) 
and a characterisation of TCs, looking at their defining features and peculiarities from the perspective of the MIC Theory (2.2). The section is closed with the description of the textual material analysed (2.3.). Section 3 is devoted to the results obtained in the analysis and their discussion. Special attention is paid to the statistical distribution of TCs in the data considering the variables of medium of expression and text type (3.1.), and the informative potential of the postverbal (nominal) constituent that functions as local CA (3.2.). Finally, in Section 4 we offer some concluding remarks.

\section{METHOD}

\subsection{Theoretical framework. The MIC Theory}

The so-called MIC Theory may be described as a development of Centering Theory, which might in turn be understood as "an account of one aspect of discourse processing, local discourse structure, that makes specific claims about both processing complexity and discourse anaphora" (Walker, Joshi \& Prince, 1998: preface) ${ }^{2}$. Centering is "a model of the conversants' center of attention in discourse that is concerned with the relationship of attentional state, inferential complexity, and the form of referring expressions" (Walker, Joshi \& Prince, 1998: 1). Such an approach to language aims to model discourse processing factors that might explain the differences in the degree(s) of coherence perceived by addressees when they receive and interpret messages.

In the Meta-Informative Centering model, the main focus is on 'meta-information' which, as already pointed out, is the label for the sequential ordering of 'information', that is, for the sequential ordering of the content of linguistic utterances. In this sense, the metainformative level "is necessary in order to achieve the ordering of non-linear mental representations as texts (sequences of linguistic utterances)" (Wlodarczyk \& Wlodarczyk, forthcoming: 1). In order to communicate such mental non-linear situations, users of the language select the element(s) they will be treating as the centre(s) of attention in their messages and predicate something about it/them. Once the centres of attention have been selected from the anchors of the situation, the user establishes a hierarchy and turns the primary (most important) one into the subject of the utterance, while the secondary centre(s) is/are turned into the object(s). According to the MIC Theory, the primary centre of attention is global and preverbal (represented in upper left nodes of phrase-markers), whereas the secondary ones are local (located in lower right nodes within the tree structure). The specific labels for one and the others are 'Global CA' and 'Local CAs', respectively.

Centering and predication are crucial notions within the MIC Theory. While centering involves selecting and highlighting one entity among others, predication implies saying something about the entity selected by the speaker as the global CA of the message (i.e. its 
topic). Thus, predication takes place when speakers produce linguistic expressions in which "some distinguished segments are highlighted as centres of attention" (Wlodarczyk \& Wlodarczyk, forthcoming: 2). From such a perspective, "no utterance can be formed in a natural language without choosing a CA and assigning to it a meta-informative Old or New status" (Wlodarczyk \& Wlodarczyk, forthcoming: 3). This implies that the meta-informative status of the CAs, as treated in this framework, concerns their oldness or newness. In other words, the meta-informative status of information concerns the way in which it is treated in the communicative event, the way speakers introduce it into their discourse. Ultimately, the old/new meta-informative status originates in the discourse strategies (partly fixed by syntactic rules) established and employed by the speaker (Wlodarczyk \& Wlodarczyk, forthcoming: 6).

\subsection{The there-construction in the MIC Theory}

With the label TC we refer to utterances as illustrated in (1):

(1) There's probably much more merit in keeping up one's bare obligations when they've become a dry duty than in doing all sorts of extras because one's feeling pious. (Martyn 1899)

The informative emptiness of the global CA (there) of the TC, as opposed to the presence of an informatively full local CA, is the defining feature of the construction. Given the requirements of the English language, the presence of the anonymous subject in TCs is compulsory, as " $[\mathrm{t}]$ he presence of an Object (as local and dependent CA) in an utterance presupposes that of a Subject (as global and main CA). In the same way the presence of a Focus presupposes that of a Topic" (Wlodarczyk \& Wlodarczyk, 2006b: 6). Therefore, the presence of an informatively full Object in the local CA position within the predicate presupposes the presence of a Subject in the global CA position, even if it is informatively empty (a dummy). In this sense, English TCs form part of the group of utterances with anonymous subjects (AS) marked by impersonal pronouns (usually called 'dummy subjects' in syntactic theories; see Wlodarczyk \& Wlodarczyk, 2006a: 13-14). In sections 2.2.1. and 3.2. below we will revisit the anonymous nature of the global CA and its consequences at the level of content processing.

\subsubsection{TCs and diathesis}

On certain occasions, the participant that occurs in the position of local CA in a TC may also occur in the position of global CA of a construction with the canonical word order Subject + Verb (+ Object), as in: 

a. There are snakes in the backyard
b. The snakes are in the backyard

In cases such as (2a) and (2b) above, the choice of one or the other type of utterance is conditioned by the speaker's communicative purposes and the coherence of the text (discourse) in which the utterance occurs. TCs illustrate the assumption that human languages have several lexical or grammatical devices to present situations and their participants, depending on which participant the speaker intends to present as a global or local CA (see Wlodarczyk \& Wlodarczyk, 2006a: 11). Many TCs are, in this sense, illustrative examples of diathesis, "[t]he grammatical device used to present the same situation from different points of view (i.e. choosing this or that participant of the situation as global CA)" (2006a: 12). As cases of diathesis, these TCs are "not mainly a problem of syntax and semantics, but (...) most of all a device belonging to the pragmatic level" (2006a: 12), and it is on this pragmatic level that the present paper will focus. Notice, however, that a good number of TCs cannot be regarded as variants or mere transformations of basic SVX utterances ${ }^{3}$.

TCs instantiating diathesis allow speakers to introduce the so-called notional subject of the utterance as the local CA, while the global CA slot is filled by a dummy (informatively empty) subject (i.e. there $)^{4}$. As pointed out above, this provides the construction with a pragmatic meta-informative dimension that should not be neglected (see Martínez-Insua, 2004; Martínez-Insua \& Pérez-Guerra, 2006; Breivik \& Martínez-Insua, 2008). In fact, the meta-informative dimension of the TC seems to be one of the most important motivations (if not the main one) for the use of the construction in cases such as (2), where a SVX version of the utterance might have been used instead.

Previous studies within the MIC framework have focused on passive/active or impersonal utterances, but no attention (to our knowledge) has been paid to TCs. Our aim here is to focus on TCs and test the hypothesis that, like passive and impersonal utterances, TCs offer further proof that diathesis is a device that belongs to the meta-informative and pragmatic level. In fact, Wlodarczyk \& Wlodarczyk's claims about diathesis seem perfectly applicable to the case of TCs:

In current linguistic theories the difficulty in explaining the different diatheses (which make it possible to linearise semantic situations in various ways) is due to the fact that diathesis is defined only as expressing the mapping between syntactic positions and semantic roles, and does not include the pragmatic meta-informative level of utterances. (Wlodarczyk \& Wlodarczyk, 2006a: 13)

Applying the notion of AS advanced by Wlodarczyk $(1994,1996)$ and Wlodarczyk \& Wlodarczyk (2006a) ${ }^{5}$, and putting them on a par with impersonal utterances, English TCs may be explained as constructions where the notional subject is demoted to the position of the 
Object (local CA), while the position of the Subject is occupied by dummy there. TCs allow speakers to introduce the active participants as local CAs (i.e. as Objects) even of intransitive verbs (appear, follow or be in examples 3-5 below), at the same time allowing the addressee to identify the global CA (i.e. Subject there) in a very general way, merely as a participant of the situation which surely belongs to a class of entities (either +hum or -hum) but without selecting any particular element of any of these classes.

(3) There appeared new members of the committee

(4) There followed a number of strong explosions that made everybody terrified

(5) There is a God

The informative value of the participant referred to as AS (i.e. the semantic content of dummy there) is, in turn, recognised by the addressee only when he/she interprets the utterance, as such a value is not explicitly expressed in the utterance.

\subsubsection{Other defining features of TCs}

As well as illustrating the phenomenon of diathesis, from the perspective of the MIC Theory, TCs are to be characterised as simple utterances. As such, they are not divided into opposed segments with respect to their New or Old meta-informative status. The global CA of the TC and their Predicate (containing the local CA) show meta-informative concordance, since both refer to the same informative significance ${ }^{6}$. As will be discussed in Section 3.2., the metainformative status of TCs is, most frequently, entirely New and, even if their local CAs may be somehow present in the preceding co(n)text, TCs are used by speakers so as to present information as new.

As shown in (1) above, (declarative) TCs contain the preverbal (normally, sentenceinitial) global CA there followed by (normally) a be-form ('s in (1)) and, at least, one major nominal local CA. The postverbal nominal constituent is normally a noun phrase. When it is followed by another noun phrase or by an adjective phrase, it is sometimes claimed in the literature (Lumsden, 1988, contra Williams, 1984) that it constitutes a Small Clause ${ }^{7}$. If the informative emptiness (expletive nature) of there is taken for granted, one may wonder why there (and not, for instance, it) is the AS which is used in TCs. In other words, does there specifically contribute to the informative value of the sentence in such a way that other dummies or ASs cannot occupy its place? Several remarks in favour of the informative emptiness of there can be adduced here. First, that there cannot be replaced with a locative expression follows from the fact that its nature is not deictic. Second, there in the constructions under investigation is, contra Allan (1971), unstressed, whereas locatives can be stressed $^{8}$. To round off this issue, in example (6) we illustrate the prototypical uses of locative there and there as an (existential, presentational) AS: 
(6) The whole meadow is over two foot under water \& we saw 7 yachts out on it. I had tea with Jones there was a don from Keble there as well, Owen. (Bruce 1775)

Another characteristic feature of TCs is that they undergo a significant degree of idiomatisation in the language since there plus the copulative or quasi-copulative verbs in the TCs constitutes, informatively speaking, a bleached starter, 'invariant particle' (Harris \& Vincent, 1980: 806) or simply a 'marker' for an existential or presentational utterance. This accounts for the tendency towards there's in the place of there is and even there are, particularly in spoken language (Meechan \& Foley, 1994). The idiomatised character of there plus be also explains the impossibility of inserting verbs other than be and the like (i.e. intensive) in the TC. In this sense, TCs with verbs other than be or other intensive verbs behave differently from TCs with be in many respects (NP+NP constraint, VPdeletion/preposing, extraction from the postverbal nominal segment, occurrence in root/embedded sentences ${ }^{9}$, subject-verb inversion, base generation versus transformational analysis, etc.; see Pérez-Guerra, 1999: 72-74 for the development of these differences).

Finally, it is worth noting that a further consequence of the emptiness of there and the verb is the informative relevance of the local CA or Object (the postverbal nominal segment), which constitutes the main informative component of the construction.

\subsection{Textual material}

The data for our analysis have been taken from four electronic corpora of English. For the IME and early Modern English (eModE) periods we have based our investigation on the findings reported in Pérez-Guerra (1999: Chapter 3), with empirical evidence from the subperiods 1ME (1420-1500), eModEI (1500-1570), eModEII (1570-1640) and eModEIII (1640-1710) of The Helsinki Corpus of English Texts (HC; Kytö, 1996). The late Modern English (lModE, 1700-1990) data have been taken from A Representative Corpus of Historical English Registers (ARCHER; see Biber et al., 1994). Finally, the LancasterOslo/Bergen Corpus of British English (LOB; see Johansson, 1978) and the British National Corpus (BNC; see Aston \& Burnard, 1997) have offered empirical information for the PDE period. Table 1 below displays the periodisation and word totals.

\begin{tabular}{|llll|}
\hline period & corpus & words in corpus & No. of words analysed \\
\hline lME & HC & 213,850 & 71,097 \\
eModEI & HC & 190,160 & 61,219 \\
eModEII & HC & 189,800 & 75,762 \\
eModEIII & HC & 171,040 & 62,940 \\
lModE & ARCHER & approx. 1.7 million words & 319,694 \\
PDE & LOB & approx. 1 million words & 98,007 \\
& BNC: spoken & approx. 10 million & 501,656 \\
& BNC: written & approx. 90 million & 505,534 \\
\hline Total & & & $1,695,909$ \\
\hline
\end{tabular}

Table 1. Periods and word totals 
The samples analysed constitute a representative selection from the corpora. In the case of the data from the HC and the LOB, we have explored eight single-spaced pages of each of the samples listed in Pérez-Guerra (1999: 297-301). In the 1ModE period, we have looked at the first passages containing not less than 5,000 words in each of the British samples of ARCHER. As regards the BNC, Martínez-Insua (2004) has used a disproportionally stratified sample of approximately 500,000 words of spoken and 500,000 of written English consisting of text-type passages with the same length.

\section{RESULTS AND DISCUSSION}

\subsection{Distribution of there in the database}

Our database comprises every declarative TC occurring in the textual material described in the previous section. The overall results are given in Table 2:

\begin{tabular}{lll}
\hline period & raw figures & normalised figures $(/ 1,000$ words $)$ \\
\hline IME & 93 & 1.3 \\
eModEI & 151 & 2.46 \\
eModEII & 126 & 1.66 \\
eModEIII & 119 & 1.89 \\
IModE & 626 & 1.95 \\
PDE & 2,892 & 2.61 \\
\hline Total & 4,007 & 2.36 \\
\hline
\end{tabular}

Variation IME>eModEI: significant (Pearson chi-square, uncorrected for continuity, is 23.89, $\mathrm{P}=<.0001$ ). Variation eModEIII>IModE: poorly significant (Pearson chi-square, uncorrected for continuity, is $0.12 ; \mathrm{P}=$ 0.729). Variation IModE $>\mathrm{PDE}$ : significant (Pearson chi-square, uncorrected for continuity, is $43.47 ; \mathrm{P}=<.0001$ )

In the light of the frequencies of the TCs portrayed in Table 2 and the ratios for the other thematic systems ${ }^{10}$, given in Pérez-Guerra (1999), one may conclude that the there-strategy has been a reasonably productive construction in all the periods under analysis. For example, the ratio of TCs amounts to a proportion of approximately 2 instances per 1,000 words, especially from eModEI to PDE. The progressive increase of TCs in the periods under investigation is the most significant finding in Table 2 (from 1.3 instances in $1 \mathrm{ME}$ to 2.61 per 1,000 words in PDE).

The PDE figures taken from the BNC allow a finer analysis of the data with respect to the distribution of TCs per medium. On the one hand, Pérez-Guerra (1999:95) accounts for the distribution of the TCs in IME and eModE according to the variable ' $\mathrm{W}$ ' used by the compilers of the HC. He reports the low frequency for the construction in written texts and 
higher numbers for the written-to-be-spoken samples. Nevertheless, the proportion of TCs in the speech-based texts is notably low. In the light of those figures, Pérez-Guerra rejects any sort of connection between oral/written language and the distribution of TCs in the IME and eModE passages. On the other hand, Martínez-Insua's (2004: 78-79) findings attested the higher frequency of the construction in speech as opposed to the written medium in PDE, which is in line with, among others, Breivik (1989: 53; 1999: 10) and Biber et al. (1999: 957), who link the frequency of TCs to the looser syntactic organisation of speech. In this vein, Martínez-Insua (2004: 79) hypothesises that the higher statistical productivity of TCs in speech should be explained by the fact that speech demands the definition of local or immediate scenarios in which the events take place, which, in the case of written production (by definition, long-lasting), can be shared by several sentences. Once a setting or scenario has been established in written discourse, it remains available for the subsequent discourse. By contrast, the on-line nature of speech requires the regular definition of scenarios. This function of TCs, commonly known as 'presentational', will be discussed in Section 3.2.

Table 3 below shows the distribution of TCs per text type. In order to investigate the connection between the frequency of the construction and the variable text type, we have limited ourselves to exploring those text types of which we have material in practically all the periods under investigation. For example, we have not investigated the Bible because, whereas the HC contains passages from the Bible, neither ARCHER nor LOB does (we have not provided totals of examples per period because, as already recognised, the text types investigated do not account for all the instances of TCs).

Two main conclusions can be reached in view of Table 3. First, the findings reveal an increase in the use of this meta-informative strategy in practically all the text types in PDE, which is in keeping with our previous remarks on the statistical consolidation of the construction in the light of the overall results in Table 2. Second, despite some minor cases of statistical disparity, Table 3 suggests that the TC occurs slightly more frequently in the letters

\begin{tabular}{|llllllll|}
\hline text type & statistics & lME & eModEI & eModEII & eModEIII & lModE & PDE \\
\hline scholarly & raw & 41 & 48 & 37 & 28 & 113 & 325 \\
& /1,000 words & 1.35 & 2.11 & 1.55 & 1.35 & 1.56 & 2.25 \\
law and social & raw & 2 & 3 & 0 & 0 & 18 & 177 \\
& $/ 1,000$ words & 0.36 & 1.42 & 0 & 0 & 1.59 & 2.86 \\
fiction & raw & 19 & 4 & 20 & 13 & 187 & 190 \\
& /1,000 words & 2.84 & 1.21 & 1.4 & 1.57 & 2.04 & 2.25 \\
letters & raw & 3 & 17 & 4 & 19 & 62 & - \\
& /1,000 words & 0.79 & 1.86 & 0.53 & 1.85 & 2.23 & - \\
sermons and & raw & 19 & 19 & 23 & 12 & 104 & 408 \\
speeches & /1,000 words & 1.09 & 3.26 & 4.5 & 2.71 & 2.77 & 3.24 \\
other formal & raw & 9 & 48 & 36 & 47 & 239 & 177 \\
writings & $/ 1,000$ words & 1.4 & 3.36 & 1.38 & 2.81 & 1.65 & 1.57 \\
\hline
\end{tabular}

Table 3. Distribution of TCs per text type 
and sermons/speeches in ModE and PDE. This would corroborate the general preference for the strategy in both the spoken and the written-to-be-spoken media, as previously discussed in this paper. The percentages are, however, so similar in the contemporary period that one can conclude that the distribution of the TC in PDE is not subject to textual categorisation. In other words, the statistical homogeneity evinced by the figures in the PDE column indicates that the TCs cannot be assessed as markers of specific text types but rather as metainformative strategies evenly selected in the various textual variants. In Johansson's (1997: 304) words, '[e]xistential there is apparently a form which is commonly needed in all registers'.

\subsection{Informative and meta-informative aspects of TCs}

Many aspects related to the informative and meta-informative organisation of TCs have been explored in the literature. Whereas some, such as the topical, locative and possessive meaning of the strategy, are beyond the scope of this paper, we will deal here with two main issues: the repairing nature of the TCs with respect to word order and the presentational or existential character of the construction. The section will be organised as follows: in Section 3.2.1 we deal with the description of TCs as a meta-informative (word-order) repairing strategy, whose main objective is to place focal information in the local CA position. Section 3.2.2 is devoted to the characterisation of these utterances as an existential/presentative strategy. In Section 3.2.3 we examine the informative configuration (information structure) of the TCs in our database. Finally, Section 3.2.4 scrutinises the definiteness restriction which is accepted to operate in the postverbal nominal segments of TCs.

\subsubsection{TCs as a meta-informative (word-order) ordering strategy}

Under standard assumptions (Kirkwood 1969, Quirk et al., 1985: 89, among others), TCs have been claimed to be syntactic strategies which allow the accommodation of notional subjects conveying unshared information in sentence-final position, thus agreeing with informative principles such as 'given before new', 'end-focus', etc. In this vein, since there has been described as an informatively vacuous marker (Section 1), and the verbs which are usually found in TCs are not informatively significant either (see Martínez-Insua \& PérezGuerra, 2006), the whole utterance is, informatively speaking, new or forward-looking. This informative newness, as a characteristic of the whole utterance yet concentrated on its Predicate (postverbal segment), implies the presentative effect of the utterance, which may thus be characterised as 'presentative' or 'presentational'.

\subsubsection{TCs as existential or presentative utterances}

TCs have generally been treated as existential or presentative utterances, and by 'existence' one refers to the presentative function of either the actual or the metaphorical appearance of a 
certain referent on stage ${ }^{11}$. From this perspective, the main goal of TCs is to bring into the hearer/speaker's awareness the referent materialised by the local CA segment as an existing entity (see Bolinger, 1977: 110-11). This cognitive process of bringing a certain entity to the attention of the hearer/speaker includes Davidse's (1999) function of 'instantiation of a general type'; in other words, the TC individualises the referent materialised by the local CA and converts it into a specific entity for the audience.

The fact that the presence of there brings about the existential reading of the local CA has led Pérez-Guerra (1999: 81ff) to hypothesise that there is not a prototypical dummy element but rather a grammaticalised meaningful discourse marker with informative consequences on the utterance in which it occurs. The informative loading of there receives support from those scholars who maintain that there has a locative flavour. In Breivik's (2000: 28) words, "[a]lthough there 1 [our there] has undergone desemanticisation and can no longer refer to a concrete location, it still carries some locative meaning. (...) There 1 designates (...) a 'mental space', i.e. a space where conceptual entities are located" (see Fauconnier 1994 for the concept of mental spaces). There would, in consequence, not be an expletive resulting from a syntactic transformation, and this would account, among other things, for the so-called sourcelessness issue. The only register of non-locative there which can be claimed to be absolutely expletive in the database is the one in (7):

(7) There was not long sithens two Roges that alwaies did associate them selues together, and would neuer seperat them selues, vnles it were for some speciall cuases, for they were sworn brothers (...): these two (Harman: 37).

Notice that the perspective adopted in this hypothesis is not historical but synchronic. From a diachronic perspective, as generally accepted in the literature (Fischer, 1992: 235, Traugott, 1992: 216, Breivik, 1999), the insertion of there in the global CA position in existential sentences is required by the verb-second syntactic requirement.

\subsubsection{Informative configuration of there-sentences}

In the previous subsections we briefly outlined the informative characterisation of the main participants in the TC. On the one hand, the local CA or Object was claimed to be forwardlooking in that it conveys new, focal, unfamiliar, unshared information, that is, information 'which the speaker assumes is not in the hearer's consciousness prior to the utterance, nor even in the hearer's current knowledge structure' (Van Oosten, 1986: 46). In other words, the local CA of TCs was claimed to convey information new to the discourse and to the hearer. On the other hand, there, as a marker of existence or presentativeness, was practically vacuous from an informative point of view. Consequently, TCs were characterised as simple utterances carrying new information. 
In Figure 1 we examine the informative content of the entities occurring as local CAs in the TCs listed in our database ${ }^{12}$. The taxonomy of referentiality which we have adopted here is very basic; we have divided the local CAs into three categories:

(i) referring (near Walker, Joshi \& Prince's, 1998 backward-looking centres)

(ii) nonreferring (close to Walker, Joshi \& Prince's, 1998 forward-looking centres)

(iii) and low-referring

'Referring' segments (in the unmarked subject in italics in (8)) are, informatively speaking, not new in the discourse domain, which, following the relevant literature (Hajicová \& Vrbová, 1981, 1982; Ariel, 1996 and Toole, 1996: 274, among others), comprises seven utterances previous to the expression and up to five utterances in the subsequent context. The 'referring' segment (or backward-looking centre) may represent a link back to an entity evoked earlier than in the immediately prior sentence, in agreement with Birner's (1998: 320) claim that "the centering algorithm may need to be made more flexible" in order to accommodate cases where centering applies to nonadjacent utterances, especially if the "intervening utterances constitute an embedded discourse segment." 'Low-referring' expressions (see the italicised prepositional complement in (9)) are instances of semiavailability, that is, when only the non-head portion of the constituent (a modifier, a complement or a conjunct) are textually available. Finally, 'nonreferring' segments (in the highlighted embedded subject in (10) below) are neither referring nor low-referring; that is, they are informatively new and therefore unavailable in the discourse.

(8) [And be itt further enacted by the Authority aforesaid That if such Sheriff Goaler or Keeper of Prison being duely su moned to appear before the said Justice or Justices of the Peace shall (...) refuse (...)] such Sheriff Goaler or Keeper (...) shall (...) (Statutes VII: 75)

(9) And than the moder sent [the sayde Edmounde] with his brother Robert to scole. And she had ii doughters, Dame Mary and Dame Alys; (...) But in a tyme as Mabely his moder put oute wolle to spynne, she toke hir spynners so moche for the libra that thaye myght not leue thereon, but complayned to [Seynt Edmond hir sonne $]_{\mathrm{j}}$. (Blake: 164)

(10) aftye his tubele \& hir gret fere it xuld ben schewyd vn-to hir sowle how pe felyngys wuld ben vndyrstondyn. (Kempe: 55) 


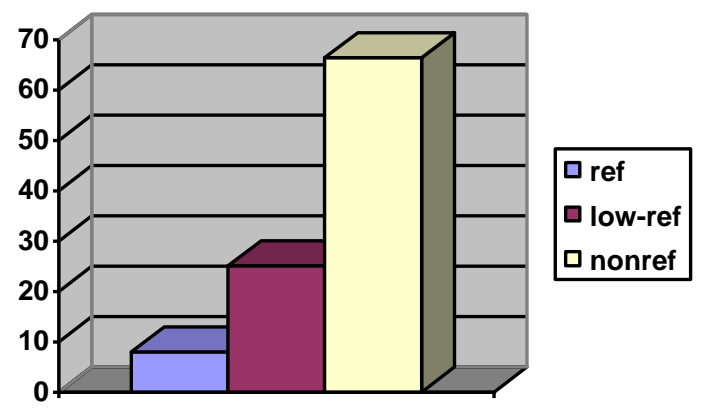

Figure 1. Informative potential of the local CAs in the TCs

The situation evinced in Figure 1 leaves no doubt as to the characterisation of the TC as a strategy whose main aim is to introduce or bring to the addressee's attention informatively new material, either (absolutely) nonreferring or (partially) low-referring. Prototypically speaking, then, the local CAs of TCs are forward-looking centres. Such a conclusion accords with our preliminary informative account of the construction in the previous subsections. Along with this, the characterisation of the postverbal slot in the TC as a carrier of new focal information is favoured by the fact that backward-looking centres (referring information) have been attested to prefer initial position within TCs. Pérez-Guerra (1999: 111) offers the detailed proportions of referring information in other constituents occurring in sentence-initial position in the TC, namely, initial adjuncts or fronted complements. According to those findings, $51.5 \%$ of such constituents convey referring information. The TC thus satisfies to a large extent the traditional principles of given-before-new and the end-focus principle, which have a prominent role in the characterisation of the strategy.

Certain connections may be established between the above mentioned features and some of the characteristic aspects of right dislocation (Grosz \& Ziv, 1998) and inverted constructions (Birner, 1998). On the one hand, as in the case of right dislocation, the joint usage of a proform (there) and a postverbal description serves to establish discourse coherence. It has already been pointed out that, as in right dislocation (Grosz \& Ziv, 1998: 294), the linguistic structure and the meta-informative features of our presentative utterances ultimately depend on their "intentional structure". The satisfaction of the discourse purpose of the TC (i.e. the introduction of a forward-looking centre in the Predicate of a simple utterance) contributes to the satisfaction of the overall communicative purpose of the discourse. On the other hand, TCs are close to inverted constructions in that the information presented in the postposed segments (e.g. the Object or local CA) is consistently less familiar within the discourse than that presented in the preposed segments (e.g. the Subject or global CA). The use of TCs is, in this sense, the result of the speaker's choice to postpone unfamiliar information and place it in the local CA position of the utterance for the sake of maintaining discourse coherence. 
As in the case of inversion, communicatively and informatively speaking, TCs help to organise the discourse "when standard reference and discourse processing are not sufficient" (Grosz \& Ziv, 1998: 305). They either help to retrieve and refocus formerly centered entities (low-referring), or constitute genuine shifts from the text to some situational entity. Like in certain cases of right dislocation, TCs are the result of the speaker's desire to shift attention to entities or situations that are "not currently sufficiently salient" (Grosz \& Ziv, 1998: 305), even if they may be present in the discourse context (either explicitly or as inferable information). The analysis of right dislocation, inversion and presentative TCs, and the centering treatment of referentiality may help to provide a unified account of the ordering of information in English.

Furthermore, besides their centering role, TCs contribute to the so-called 'Centering Rule 2' (Walker, Joshi \& Prince, 1998: 4), in that they help to soften 'rough-shift transitions'. As expressed by Walker, Joshi \& Prince (1998), Centering Theory includes a set of rules and constraints. According to the second centering rule, the transitions among the utterances in a discourse segment are ordered. Even if there are different types of possible transitions from one utterance to another, some of them are preferred over the others (" $[t]$ he CONTINUE transition is preferred to the RETAIN transition, which is preferred to the SMOOTH-SHIFT transition, which is preferred to the ROUGH-SHIFT transition" 1998: 4). In essence, this implies that strategies such as TCs, which may favour the continuity of a given CA, or a smooth-shift from one CA into another, may be preferred by speakers under certain circumstances. Thus, under certain discursive and contextual circumstances, the TC may be the preferred transition (see Walker, Joshi \& Prince, 1998: 5-6 on the notions of transition and transition state), or a more coherent kind of transition between utterances because it requires less processing time than other utterances.

Finally, it seems worthwhile mentioning that, according to our findings, the informative description of the major participants in a TC has not undergone significant diachronic changes, since the itemised results per period are quite homogeneous (see Pérez-Guerra, 1999: 111-12 for further discussion).

\subsubsection{The 'definiteness restriction'}

The indefinite character of the nominal Objects is said to be a constraint resulting from the communicative nature of TCs. This is usually described in terms of the so-called 'definiteness restriction', which blocks the occurrence of definite nominal segments (including proper nouns, personal and demonstrative pronouns, noun phrases headed by definite or possessive determiners, as well as the quantifiers all, every or each) in the local CA position of the TC.

The literature on this issue of (in)definiteness in TCs is abundant, and includes approaches to the topic from a wide variety of perspectives. In general, explanations range from those based on the dichotomy definite versus indefinite (Baker 1973; Jenkins 1975; Freeze 1992), to more flexible standpoints built around the concepts of context and (non- 
)contextualised existentials (Holmback 1984; Hannay 1985; Abbott 1993, 1997; Birner \& Ward 1998). From a formal point of view (Safir 1985), definiteness has been described as a formal property of determiners. On other occasions, it has been taken as a conceptual category (Bolinger's 1977 distinction between 'grammatical definiteness' and 'semantic definiteness'), whereas a number of scholars have defined the notion by making reference to the assumptions that senders have about the degree of identifiability that the referent presents for the addressee (Ward \& Birner's 1995 and Birner \& Ward's 1998 distinction between 'hearer old/new' and 'discourse old/new').

Despite the apparent plausibility of the combination of newness and indefiniteness as constraints imposed on the postverbal constituents, real language has always provided examples of definite articles, demonstratives, and even personal pronouns and proper nouns in postverbal position:

(11) Well, thou art the maddest Fellow, sure there is not your Peer in France (Trotter 1701)

(12) And behind him there was little Dutch, crawling with her belly down, and her eyes turned up at us, as if we were dragging her to be hanged. (Blackmore 1872)

(13) And yet in the subsequent reaches of the great argument, of which these dark regions form the preface, there emerges the clear, calm, steady light of my optimistic text. (Austen 1979)

Most of the literature on the issue attempts to account for the definite elements in existentials by resorting to concepts such as the familiarity, uniqueness, inclusiveness and identifiability of the local CA. Nevertheless, the fuzzy boundaries between such concepts do not help in the effort to find a conclusive explanation for the compatibility of the definiteness restriction and examples such as (11)-(13). What has to be taken into account here is that the Old/New status is speech-oriented. That is, it corresponds to the way in which information (content) is introduced into discourse "with reference to the conceptual pair anaphora and cataphora. (...) In such case, information is validated as $\mathrm{O}[\mathrm{ld}]$ or $\mathrm{N}[\mathrm{ew}]$ not by the knowledge about it, but by the very way it is treated in discourse" (Wlodarczyk \& Wlodarczyk 2008: 119). Consequently, the Old/New opposition depends on the speaker's desire to present information as either Old or New to the addressee's attention whatever may be the status of such information in common knowledge or in previous context. If one accepts this, one opens the possibility for entities already quoted in the text to be treated as new in subsequent parts of the same text, simply because they enter new situations or new relations. This, in turn, provides a plausible account for the possible occurrence of definite nominal segments as local CAs in TCs.

In short, rather than a question of (in)definiteness, the requirement imposed on the nominal local CA of the TC is that it should be communicatively pertinent to (re)introduce its 
referent at the specific point of the communication in which it occurs. The communicative and informative saliency of such local CAs and the speaker's choice to present them as new to the hearer provide the explanation that formal approaches failed to provide for the socalled definiteness restriction. Table 4 below displays the distribution of TCs with definite local CAs in our database:

\begin{tabular}{|cccccc|}
\hline IME & eModEI & eModEII & eModEIII & lModE & PDE \\
\hline $4 / 93$ & $13 / 151$ & $17 / 126$ & $5 / 119$ & $65 / 626$ & $172 / 2,892$ \\
$(4.3 \%)$ & $(8.6 \%)$ & $(13.4 \%)$ & $(4.2 \%)$ & $(10.38 \%)$ & $(5.94 \%)$ \\
\hline
\end{tabular}

Table 4. Definite noun phrases in the local CAs of $\mathrm{TCs}^{13}$

Although the frequency of TCs with definite Objects is not high, their proportion is reasonably significant, especially if we consider the figures for eModEI, eModEII and IModE. Our findings confirm the presence of definite postverbal segments in TCs across time, as well as their acceptability, provided that they present information that is salient for the discourse. In Hannay's (1985: 101) words, “definite terms may occur quite naturally in existentials on condition that their pragmatic status is not in conflict with the function of the existential predication". This indicates a progressive consolidation (or grammaticalisation) of the TC as a scheme of mood in which the there-strategy is becoming a new type of declarative mood pattern rather than an alternative to the unmarked SVX organisation.

\section{CONCLUDING REMARKS}

In this paper we have carried out a corpus-driven investigation on the distribution of TCs from IME to PDE. The findings lead to the conclusion, first, that the TC is productive in all periods and, second, that its frequency increases progressively, which underlines the statistical consolidation of the strategy in the recent history of the language. Higher proportions of TCs are detected in speech and in speech-based texts, especially in PDE. The homogeneous distribution of TCs among the text types in PDE is in keeping with the hypothesis that this meta-informative strategy has consolidated itself in later periods. In fact, it has been suggested that the TC can be taken as a specific scheme of the declarative mood, which received support from the progressive grammaticalisation of the structure around an invariable there's marker, even with plural local CAs.

Prototypically, in the TC a nominal local CA is placed in the Predicate, in sentence-final or, at least, postverbal position, while an AS occupies the unmarked (preverbal) global CA position. Informatively speaking, the local CAs are not only informatively new (forwardlooking, discourse-unfamiliar, or nonreferring centres), but also indefinite and pragmatically salient in the discourse. In this line, the previous sections of the paper show that TCs have the 
capacity to serve discourse coherence by continuing with the same local topics as previous utterances, as 'smooth-shift' transitions from one CA to another.

\section{ACKNOWLEDGEMENTS}

This research has been funded by the Spanish Ministry of Education and Science (grant number HUM200502351/FILO), the European Regional Development Fund and Xunta de Galicia (INCITE08PXIB204016PR; Directorate General for Scientific and Technological Promotion, grant CN2011/011), and this support is hereby gratefully acknowledged. The investigation is part of a larger project on the degree of variation experienced by the English language in its recent history as far as the syntax and structure of clausal constituents is concerned. We would like to acknowledge the comments raised by the project members, especially by the group leader Javier Pérez-Guerra, whose unfailing collaboration in the analysis of the data has been crucial to the completion of the study.

\section{NOTES}

1. While 'informative layer' refers to the propositional meaning of the message, 'meta-informative' refers to the linear distribution of the propositional meaning, that is, word order. See following paragraphs and Section 2 for further details.

2. Centering, as defined by Walker, Joshi \& Prince (1998: 2), is a synthesis of the two above mentioned strands of earlier work: first, research by Joshi and Kuhn (1979) and Joshi and Weinstein (1981), and secondly, research conveyed by Grosz (1977), Sidner (1979), and Grosz and Sidner (1986).

3. Much attention has been paid, especially in formal accounts of TCs, to issues such as the socalled 'leftmost be condition', 'predicate restriction' or 'sourcelessness issue'. Even though, to the best of our knowledge, they have not been approached from the perspective of the MIC Theory, constraints of time and space compel us to leave the question open to further research.

4. Pérez-Guerra (1999: 105) reports that in late Middle English about two thirds of the theresentences could be adapted to a non-there $\mathrm{SV}(\mathrm{X})$ configuration. In the late Modern English corpus (see Section 2), 49.36\% (309/626) of examples might have a corresponding SV(X) variant. In the present-day English data, only a quarter of instances would allow such a transformation (77.43\% - 2,083/2,690 - in the British National Corpus). This might suggest that the TC was an alternative to the unmarked organisation in older English and has evolved into a specific word-order variant in contemporary English not necessarily tied to the unmarked ordering of clausal constituents.

5. As defined by Wlodarczyk (1994: 670; 1996: 181), AS (including existential there) can be defined as "lexèmes (éventuellement de forme morphonologique zero) dont le critère définitoire est qu'ils ne peuvent apparaître que dans la position syntaxique de sujet."

6. Notice that, even if there is a dummy or (informatively) empty element, there is a referential relationship that links it with the local CA in the Predicate.

7. For the concept of Small Clause, see, for instance, Haegeman (1994: $123 \mathrm{ff}$ ). This analysis is also suggested by Hale \& Keyser (2002: 189) for those instances of unaccusative verbs participating in the TC.

8. See Pérez-Guerra (1999: 64-67) for other linguistic differences between there-constructions and sentences with locative there. See Kaiser (2000) for the syntactic treatment of there as a locative argument of the verb.

9. The figures given in Pérez-Guerra (1999: 105) show a statistically significant difference between IME and PDE in the percentage of TCs in embedded positions. This demonstrates that the construction is likely to occur both in root and in embedded contexts. The results also indicate a remarkable decrease in the number of non-root TCs over time: from $17.2 \%$ in $1 \mathrm{ME}$ to $2.9 \%$ in the LOB PDE data. This fact is in line with the characterisation of the TC as a specific word-order 
variant not necessarily connected to the unmarked configuration. The informative characterisation of the construction will give support to the previous hypothesis.

10. See Halliday (1994), among others, for the definition and analysis of the so-called thematic systems.

11. In this paper we use the terms 'existential' and 'presentative/presentational' indistinctly, whereas such a distinction is frequently maintained in the literature (Hannay 1985, Huddleston \& Pullum 2002).

12. The data are based exclusively on the HC and LOB samples. The period lModE has not been investigated in terms of referentiality since we have not had access to the context of the examples containing there.

13. We included in this group nominal CAs initiated by the definite determiner the, demonstratives, possessives, such (a), names (proper nouns) and nouns which belong to the permanent registry of universal referents (love, truth, death, pain, silence).

\section{Primary sources}

Aids $=(1991)$ Aids care education \& training. London. (bnc a0_116)

Austen, J. (1979). 2nd ed. Jane Austen's letters to her sister Cassandra and others. Ed. R.W. Chapman. Oxford: Oxford University Press. (archer 1800aust.x5)

Blackmore, R.D. (1872). The maid of Sker. (archer 1872blac.f6)

Blake, N. F. c. 1450 (1438). The Life of St. Edmund. London: Edward Arnold. (helsinki q_m4_nn_bil_edmund)

Bruce, J. Some observations upon Myrrh .... Phil Trans. 65:408. (archer 1775bruc.s3)

Coventry, F. (1751). The history of Pompey the Little: or the life and adventures of a lap-dog. (archer 1751cove.f3)

Harman, Th. (1567). A caveat or warening for commen cursetors vulgarely called vagabones. Ed. E. Viles and F.J. Furnivall $(1937$ (1869, 1898)). London [Early English Text Society, E.S. 9]. hc q_e1_ni_fict_harman)

Kempe, M. a. (1438). The book of Margery Kempe, Vol. I. London [Early English Text Society, 212] (ed. S.B. Meech and H.E. Allen). (helsinki q_m4_ir_relt_kempe)

Martyn, E. (1899). The heather field. (archer 1899mart.d6)

Statutes VII. (1695-99). The statutes of the Realm. Printed by command of His Majesty King George the Third in pursuance of an address of the House of Commons of Great Britain, Vol. VII. London: Dawsons of Pall Mall. (helsinki q_e3_sta_law_stat7)

Trotter, C. (1701). Love at a loss, or, most votes carry it. Ed. E.L. Steeves ed. The plays of Mary Pix and Catharine Trotter, Vol. II. (archer 1701trot.d2)

\section{REFERENCES}

Abbot, B. (1993). A pragmatic account of the definiteness effect in existential sentences. Journal of Pragmatics, 19, 39-55.

Abbot, B. (1997). Definiteness in existentials. Language, 73, 103-108. 
Allan, K. (1971). A note on the source of there in existential sentences. Foundations of Language, 7, $1-18$.

Ariel, M. (1996). Referring expressions and the $+/-$ coreference distinction. In T. Fretheim \& J.K.Gundel (Eds.), Reference and referent accessibility (pp. 13-35). Amsterdam: John Benjamins.

G. Aston \& Burnard, L. (1997). The BNC handbook. Exploring the British National Corpus with SARA. Edinburgh: Edinburgh University Press.

Baker, C.L. (1973). Definiteness and indefiniteness in English. Bloomington, In.: Indiana University Linguistics Club.

Biber, D., Finegan, E. \& Atkinson, D. (1994). ARCHER and its challenges: compiling and exploring a representative corpus of historical English registers. In U. Fries, G. Tottie \& P. Schneider (Eds.), Creating and using English language corpora (pp. 1-14). Amsterdam: Rodopi.

Biber, D., Johansson, S., Leech, G., Conrad, S. \& Finegan, E. (1999). Longman grammar of spoken and written English. Harlow: Longman.

Birner, B.J. (1998). Recency effects in English inversion. In M.A. Walker, A.K. Joshi \& E.F. Prince (Eds.), Centering Theory in discourse (pp. 309-323). Oxford: Clarendon Press.

Birner, B.J. \& Ward, G.(1998). Information status and noncanonical word order in English. Amsterdam: John Benjamins.

Bolinger, D. (1977). Meaning and form. London: Longman.

Breivik, L.E. (1989). On the causes of syntactic change in English. In L.E. Breivik \& E.H. Jahr (Eds.), Language change: contributions to the study of its causes (pp. 29-70). Berlin: Mouton de Gruyter.

Breivik, L.E. (1999). On the rhetorical function of existential there. Nordlit 6, 3-14.

Breivik, L.E. (2000). On relative clauses and locative expressions in English existential sentences. View [z] 9(1), 6-28.

Breivik, L.E. \& Martínez-Insua, A.E. (2008). Grammaticalization and non-concord in existential sentences. English Studies 89(3), 351-362.

Brennan, S.E., Walker Friedman, M. \& Pollard, C.J. (1987). A Centering approach to pronouns. Proceedings of the $25^{\text {th }}$ annual meeting of the association for computational linguistics (pp. 155162). Stanford.

Davidse, K. (1999). The semantics of cardinal versus enumerative existential constructions. Cognitive Linguistics, 10, 203-250.

Fauconnier, G. (1994 [1985]). Mental spaces: Aspects of meaning construction in natural language. Cambridge: Cambridge University Press.

Fischer, O. (1992). Syntax. In N. Blake (Ed.), The Cambridge history of the English language, Vol. 2 (pp. 207-408). Cambridge: Cambridge University Press.

Freeze, R. (1992). Existentials and other locatives. Language, 68, 553-595.

Grosz, B.J. (1977). The representation and use of Focus in dialogue understanding. Technical report number 151 (Menlo Park, California, SRI International).

Grosz, B.J. \& Sidner, C.L. (1986). Attentions, intentions and the structure of discourse. Computational Linguistics. 12, 175-204.

Grosz, B.J. \& Ziv, Y. (1998). Centering, global focus, and right-dislocation. In M.A. Walker, A.K. Joshi, \& E.F. Prince (Eds.), Centering Theory in discourse (pp. 293-307). Oxford: Clarendon Press. 
Haegeman, L. (1994). Introduction to Government \& Binding theory. (2nd edn). Oxford: Blackwell.

Hajicová, E. \& Vrbová, J. (1981). On the saliency of the elements of the stock of shared knowledge. Folia Linguistica 15, 291-303.

Hajicová, E. \& Vrbová, J. (1982). On the role of the hierarchy of activation in the process of natural language understanding. In J. Horecky (Ed.), Coling 82. Proceedings of the Ninth International Conference on Computational Linguistics (pp. 107-113). Prague: Academia.

Hale, K. \& Keyser, S.J. (2002). Prolegomenon to a theory of argument structure. Cambridge, MA: MIT Press.

Halliday, M.A.K. (1994). An introduction to Functional Grammar. (2nd edn). London: Edward Arnold.

Hannay, M. (1985). English existentials in functional grammar. Dordrecht: Foris.

Harris, M. \& Vincent, N. (1980). On zero relatives. Linguistic Inquiry, 11, 805-807.

Harris, Z. (1957). Cooccurrence and transformation in linguistic structure. Language 33/2, 283-340.

Holmback, H. (1984). An interpretative solution to the Definiteness Effect problem. Linguistic Analysis 13, 195-215.

Huddleston, R. \& Pullum, G.K. (2002). The Cambridge grammar of the English language. Cambridge: Cambridge University Press.

Jenkins, L. (1975). The English existential. Tübingen: Max Niemeyer Verlag.

Johansson, S. (1978). Manual of information to accompany the Lancaster-Oslo/Bergen Corpus of British English, for Use with Digital Computers. Oslo: Department of English, University of Oslo.

Johansson, S. (1997). A corpus study of English existential clauses: register variation and discourse function. In T. Nevalainen \& L. Kahlas-Tarkka (Eds.), To explain the present: studies in the changing English language in honour of Matti Rissanen (pp. 303-18). Helsinki: Société Néophilologique.

Joshi, A.K. \& Kuhn, S. (1979). Centered logic: the role of Entity Centered Sentence Representation in natural language inferencing. Proceedings of the 6th international joint conference on artificial intelligence (pp. 435-439). Tokyo.

Joshi, A.K. \& Weinstein, S. (1981). Control of inference: role of some aspects of discourse structurecentering. Proceedings of the 7th international joint conference on artificial intelligence. (pp. 385387). Vancouver.

Kaiser, A. (2000). Subject-there as an adverb. In H. Janssen (Ed.), Verbal projections (pp. 142-62). Tübingen: Max Niemeyer Verlag.

Kirkwood, H. W. (1969). On the thematic function and syntactic meanings of the grammatical subject in English. Linguistische Berichte 9, 35-46.

Kytö, M. (1996). Manual to the diachronic part of the Helsinki Corpus of English Texts: coding conventions and lists of source texts. Helsinki: Department of English, University of Helsinki.

Lumsden, M. (1988). Existential sentences: their structure and meaning. London: Croom Helm.

Martínez-Insua, A.E. (2004). Existential there-constructions in contemporary British English: a corpus-driven analysis of their use in speech and writing. München: Lincom Europa.

Martínez-Insua, A.E. \& Pérez-Guerra, J. (2006). “'There's Björg': on there-sentences in the recent history of English". In L.E. Breivik, S. Halverson and K.E. Haughland (Eds.), 'These things write I vnto thee...'. Essays in honour of Björg Baekken (pp. 189-211). Oslo: Novus Press. 
Meechan, M. \& Foley, M. (1994). On resolving disagreement: linguistic theory and variation - there's bridges. Language Variation and Change, 6, 63-85.

Pérez-Guerra, J. (1999). Historical English syntax: a statistical corpus-based study on the organisation of Early Modern English sentences. München: Lincom Europa.

Quirk, R., Greenbum, S., Leech, G. \& Svartvik, J. (1985). A comprehensive grammar of the English language. London: Longman.

Safir, K.J. (1985). Syntactic chains. Cambridge: Cambridge University Press.

Sidner, C.L. (1979). Toward a computational theory of definite anaphora comprehension in English. Technical report number AI-TR-537. Cambridge, Mass.: MIT Press.

Toole, J. (1996). The effect of genre on referential choice. In Torstein Fretheim and Jeanette K. Gundel (Eds.), Reference and referent accessibility (pp. 263-290). Amsterdam: John Benjamins.

Traugott, E.C. (1992). Syntax. In R.M. Hogg (Ed.), The Cambridge history of the English language, Vol. 1 (pp. 168-289). Cambridge: Cambridge University Press.

Van Oosten, J. (1986). The nature of subjects, topics and agents: a cognitive explanation. Bloomington, IN.: Indiana University Linguistics Club.

Walker, M.A., Joshi, A.K. \& Prince, E.P. (1998). Centering in naturally occurring discourse: an overview. In M.A. Walker, A.K. Joshi \& E.F. Prince (Eds.), Centering Theory in discourse (pp. 128). Oxford: Clarendon Press.

Ward, G. \& Birner, B.J. (1995). Definiteness and the English existential. Language, 71, 722-741.

Williams, E. (1984). There-insertion. Linguistic Inquiry, 15, 131-153.

Wlodarczyk, H. (1994). Les phrases à sujet anonyme et verbe réfléchi en polonais et en russe. Organisation sémantique de la phrase dans les langues slaves. (Revue des Etudes Slaves T. LXVI 3), 669-680.

Wlodarczyk, H. (1996). Les traits sémantiques du sujet "anonyme" en polonais, russe et français. Semantyka a konfrontacja językowa (pp. 179-198). Warszawa: Akademia Nauk, Instytut Slawistyki, Slawistyczny Ośrodek Wydawniczy.

Wlodarczyk, A. \& Wlodarczyk, H. (2006a). Subject in the Meta-Informative Centering Theory. Études cognitives / Studia kognitywne VII, 7-32.

Wlodarczyk, A. \& Wlodarczyk, H. (2006b). Focus in the Meta-Informative Centering Theory. La Focalisation dans les langues. Collection Sémantiques, L'Harmattan. Paris.

Wlodarczyk, A. \& Wlodarczyk, H. (2008). The pragmatic validation of utterances. Études cognitives / Studia kognitywne, VIII, 117-128.

Wlodarczyk, A. \& Wlodarczyk, H. Forthcoming. Meta-Informative Grounding of Utterances. 